\title{
IMPORTANCE OF EDUCATION AND TRAINING OF YOUNG NOVICE DRIVERS
}

\author{
Tatiana Hajdúková \\ Academy of the Police Force in Bratislava \\ 1 Sklabinská str., Bratislava, Slovak Republic, 83517 \\ tatiana.hajdukova@minv.sk \\ Daniela Becková \\ Academy of the Police Force in Bratislava \\ 1 Sklabinská str., Bratislava, Slovak Republic, 83517 \\ dbeckova5@gmail.com
}

\begin{abstract}
An important element of internal safety of a society is the maintenance of a functioning transport connection throughout the territory of the country. The line between safety and unsafety is often very thin. That is why we cannot explore safety without being aware of the danger. The study evaluates the development and current state of the road traffic accidents resulting in the death of road users in EU countries. Attention is paid to the countries with the best results of fatal accidents, which are examples of good practice for other countries. The slowdown in improving EU results over recent years is evidence that the most effective remedial measures have already been applied. The results of other measures will no longer be as effective as they have been so far and will require more money, energy and effort to be invested with slower progress than 15 years ago.

The analytical part of the study points to the causes of traffic accidents resulting in injury or death of the road users in Slovakia. Multidimensional scaling has been used to identify differences in the causes of traffic accidents according to the age of drivers, the culprits of traffic accidents. The results point to the need for a graduated licensing system for young novice drivers.
\end{abstract}

Keywords: safety, road traffic accident, fatalities, training, licensing, young driver, experience, injury.

\section{Introduction}

Mobility is a fundamental prerequisite for quality of life. Walking is one of the most natural activities for humans. However, due to speed of walking and distance we are able to cover, as well as natural human laziness, the most common means of transport is road traffic. In the present, road communications have been well established, which is a prerequisite for their intensive use in the future. Besides the obvious benefits, gained from road transport, it also has negative accompanying effects, such as traffic accidents. However, the seriousness of the consequences of traffic accidents is perceived by the community sensitively and with full respect [1]. The long term goal of traffic safety should be that not a single person is killed or seriously injured as a consequence of traffic collisions within the road transport system [2]. Vision Zero [3] has a scientific foundation, with a focus on kinetic energy as the real cause of deaths and serious injuries, as proposed by De Haven [4]. Indeed, various accident commissions of inquiry have reached the conclusion that the road user is the cause of over $90 \%$ of all road accidents [5].

Traffic Accident

There is no intergovernmental, unified, definition of a traffic accident. The most common indicators of traffic accidents are:

- The amount of property damage;

- Number of road users with minor, major and fatal injuries.

The most serious consequence of traffic accidents is death of a person. In this article, we define road fatality as death of a person, which resulted from a traffic accident, as a direct consequence, within 30 days from the occurrence of the accident.

A comprehensive analysis of the global transport demanded trend over the next forty years, which was presented by the JTRC/ITF in May 2011 in Leipzig (OECD/ITF, 2011) [6]. There is a wide range of factors, falling under several disciplines, which all affect the potential road safety. There are widely discussed topics between men and machines; among them especially accident 
simulation tests, design of vehicle interior and body, as well as occupant and pedestrian protection, accident avoidance scenarios, injury mitigation, legislation and technology changes [7].

\section{Aim of research}

Improving road traffic safety has high priority in all countries [8]. The aim of this study is to put focus on road traffic safety on the international scale, and for this purpose we use comparative data from 28 countries of EU. Multiple comparisons have been made during the past ten years. Based on analysis of causes of road traffic accidents with injury or death that occurred in Slovakia, we select only those, where a driver of a motor vehicle is held responsible, and we deal with specific safety issues, concerning frequent speeding. Furthermore, we point out age of drivers as the main contributing factor in speeding traffic accidents, which result in injury or death of traffic participants.

\section{Methodology}

In this article the safety on the road is expressed in terms of road mortality and injury rates. Source data consists of traffic accidents provided by the European Commission and the ISDN system of the Police Headquarters of the Slovak Republic.

We provide an overview of the latest road safety data and the main road safety development trends in the EU from 2007 to 2017. Furthermore, we differentiate and compare the results of the fatal traffic accidents in the EU Member States. Traffic accident comparisons aim to point out differences in the achieved results. We especially focus on development trends in the countries with the best and the worst results. Considering the different size of countries and the number of their inhabitants, we used single population mean to standardize data on traffic accidents, i. e. the number of persons, killed in road collisions, divided by their population size. Knowledge of the causes of traffic accidents is crucial for introducing measures to reduce them. We have specified the causes of fatal traffic accidents and proposed possible measures for the current conditions in the Slovak Republic.

This study aims to put together recommendations to increase road safety by identifying causes of traffic accidents with regard to age of people, who are responsible for the traffic accident.

\section{Result}

4. 1. Status and development of fatal road accidents of road users in European Union

A need for safety and security is one of the basic needs in life of every person. As the most tragic consequence of a traffic accident is the death of a road user, it is important to pay attention to this issue. Reducing the number of road casualties requires continuous action, based on the analysis of good quality road safety data [9]. The EU28 reduced the number of road deaths by $20 \%$ between 2010 and 2017, but it is a way behind in progress, needed for the 2020 target of cutting death by half over this decade (Fig. 1).

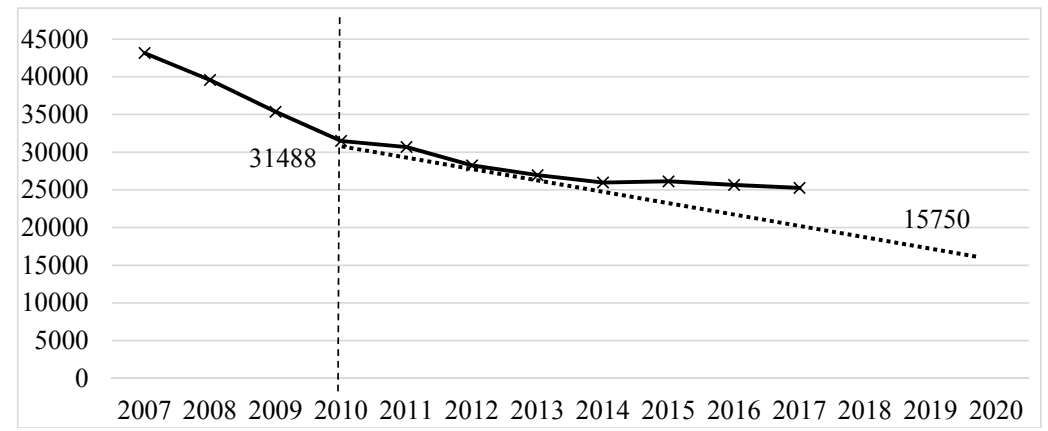

Fig. 1. Road fatalities in the EU since 2001.

Source of data: European Commission with target EU 2020 [10]

From the results, shown in Fig. 1, some stagnation and a moderate lag behind the targeted values are observable for years 2015 and later. Differences between regions and estimation of po- 
tential room for improvement can be identified, based on the distinction between the smaller EU territorial units, which are in this case individual states, as shown in Fig. 2.

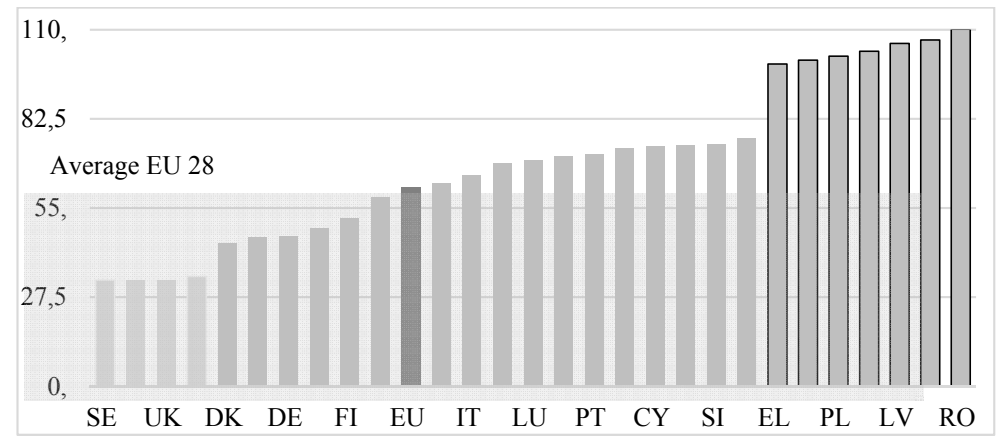

Fig. 2 Number of people, killed in road traffic accidents, per million inhabitants by country, in average for years 2007-2017.

Source of Data: Eurostat, [11] and national statistics

The average of the EU-28 countries for period 2007 to 2017 is 49 fatalities in road traffic accidents per million inhabitants. The best road fatality rates are reported from Sweden, Malta, United Kingdom and Netherlands, counting in average less than 40 dead people per one million citizens [9]. The traffic safety has been a long term goal [12].

By contrast, the worst results, exceeding 100 people killed in road traffic accidents per million inhabitants, were achieved in Greece, Croatia, Poland, Bulgaria, Latvia, Lithuania and Romania. 11 years is a long period, such that there are significant changes in the road traffic dynamics. Fig. 3 shows the development of the number of road traffic fatalities per million inhabitants, but we filtered out mediocre countries, leaving only those, which achieved the worst and the best results.

The European Union average is shown in the graph with the grey background. Sweden, United Kingdom and Netherlands showed stable or slightly improving results throughout the recorded period. Their transport safety shows clear signs of well-designed and functioning systematic measures. The low road traffic fatality rate in Sweden (2.8 per 100,000 inhabitants in 2010) and road safety policy in general (Vision Zero in particular) have roots in a long tradition of systematic road safety work, which involves taking key political decisions by the Government and Parliament [13].

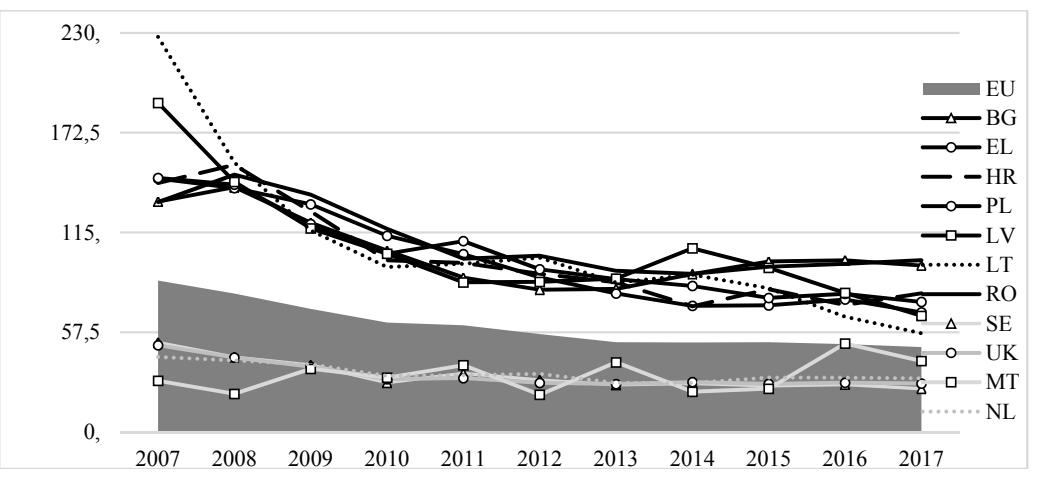

Fig. 3. Development of fatality rates in the selected countries of European Union, 2007-2017. Source of Data: Eurostat, [11] and national statistics

Slightly fluctuating results with a tendency for deterioration are observable in Malta where there is a plausible indication of the presence of unresolved problems. The situation in Malta is a clear evidence that it is not enough to achieve good results, comparable efforts have to be put in in order to maintain such results. We can observe a significant progress over the past 11 years in the countries, which started with the worst fatality rates in 2007 . The latest results demonstrate the successful implementation of measures in practice, particularly in Latvia, where the annual number of 
fatalities has dropped from 190 to 80 per million inhabitants. The mentioned decline in Latvia over the past 11 years reached almost $60 \%$, to the extent that it is close to the EU average for the year 2017. In principle, it is possible to note, that the lagging countries are gradually catching up to the EU average. The worst results were recorded in neighboring countries in the southern EU, Romania and Bulgaria, particularly in 2015, 2016 and 2017. The declining trend in the number of people, killed in traffic accidents, that was recorded in those countries in 2007 had stopped in 2013 and has been stagnating since. While several countries have made good progress in reducing fatalities by more than one-third since 2010 (which is about the average reduction, required to halve fatalities by 2020), the majority of countries are not achieving what is needed [9].

\section{2. The causes of traffic accidents with injuries and deaths, caused by the driver of a motor vehicle in Slovakia}

An objective assessment of the situation is an important prerequisite for revealing potential areas of improvement. In May 2018, The Commission published a Strategic Action Plan on road safety that includes a new long term target to halve road death by 2030 as well as for the first time, a target to reduce serious injuries by the same amount. Taking into consideration the development of the past years, presented in Fig. 1, 3, the fulfilment of this goal will not be straightforward. In order to employ effective measures, conditions and causes of traffic accidents must be thoroughly considered. Road accidents occur for a variety of reasons. Determining causes of traffic accidents is the responsibility of the police. Below, we analyzed the causes of traffic accidents on the data available from the police database of Slovakia. Over the past 11 years, Slovakia has achieved slightly worse results than the EU average (Fig. 2), so it is still at the stage of catching up to the more developed countries, like most European Union countries. During the monitored period, 41,578 traffic accidents, where a person was injured or killed, occurred. The distribution of causes of traffic accident in both absolute and relative numbers is shown in Table $\mathbf{1 .}$

\section{Table 1}

Detailed causes of traffic accidents with injury or death, caused by motor vehicle drivers in Slovakia, 2007-2018

\begin{tabular}{clccc}
\hline No. & \multicolumn{1}{c}{ Cause } & Number of TA & Relative Frequency & Total \\
\hline 1 & Violating driver duties & 12430 & $30.29 \%$ & $29.89 \%$ \\
2 & Speeding & 8603 & $20.96 \%$ & $20.69 \%$ \\
3 & Improper crossing at an intersection & 4720 & $11.50 \%$ & $11.35 \%$ \\
4 & Violating pedestrian regulations & 2422 & $5.90 \%$ & $5.82 \%$ \\
5 & Failure to respect min. distance between vehi- & 2372 & $5.78 \%$ & $5.70 \%$ \\
6 & cles & & $5.57 \%$ & $5.50 \%$ \\
7 & Violating duties of a traffic participant & 2288 & $5.45 \%$ & $5.38 \%$ \\
8 & Inappropriate style of driving & 2240 & $4.65 \%$ & $4.58 \%$ \\
9 & Risky overtaking & 1908 & $3.10 \%$ & $3.06 \%$ \\
10 & Improper turning over and reversing & 1274 & $2.79 \%$ & $2.75 \%$ \\
11 & Improper road entering & 1147 & $1.51 \%$ & $1.49 \%$ \\
12 & Improper driving in lane & 621 & $0.90 \%$ & $0.89 \%$ \\
13 & Violating cyclist regulations & 371 & $0.70 \%$ & $0.69 \%$ \\
14 & Wrong waiting and parking & 288 & $0.47 \%$ & $0.46 \%$ \\
15 & Improper circumvention/ride about & 195 & $0.35 \%$ & $0.35 \%$ \\
& Total & 147 & $100 \%$ & $98.67 \%$
\end{tabular}

Source of data: ISDN [14]

The most common cause of traffic accidents is violation of driver duties, most often in form of distracted driving [15]. Combined with the second most frequent cause, driving over speed limit, 
we get more than half of the observed traffic accidents. The second parameter which we consider is the driver's age. We base this on the assumption that the age of the driver could be a disrupting element for the real causes. In Table 2 and Fig. 4, we can see results of applying Multidimensional Scaling, used to identify age anomalies with regard to causes of traffic accidents.

Table 2

Model Summary of Optimal scaling of causes of traffic accidents with injuries and deaths by driver's age, Slovak Republic 2007-2018

\begin{tabular}{ccccc}
\hline & \multicolumn{4}{c}{ Model Summary } \\
\hline \multirow{2}{*}{ Dimension } & \multirow{2}{*}{ Cronbach's Alpha } & \multicolumn{3}{c}{ Variance Accounted For } \\
\cline { 3 - 5 } & & Total (Eigenvalue) & Inertia & \% of Variance \\
\hline 1 & 1,000 & 14,000 & 1,000 & 100,000 \\
2 &, 998 & 13,564 & 0,969 & 96,889 \\
Total & & 27,564 & 1,969 & 98,445 \\
Mean &, $999^{\text {a }}$ & 13,782 & 0,984 &
\end{tabular}

a. Mean Cronbach's Alpha is based on the mean Eigenvalue.

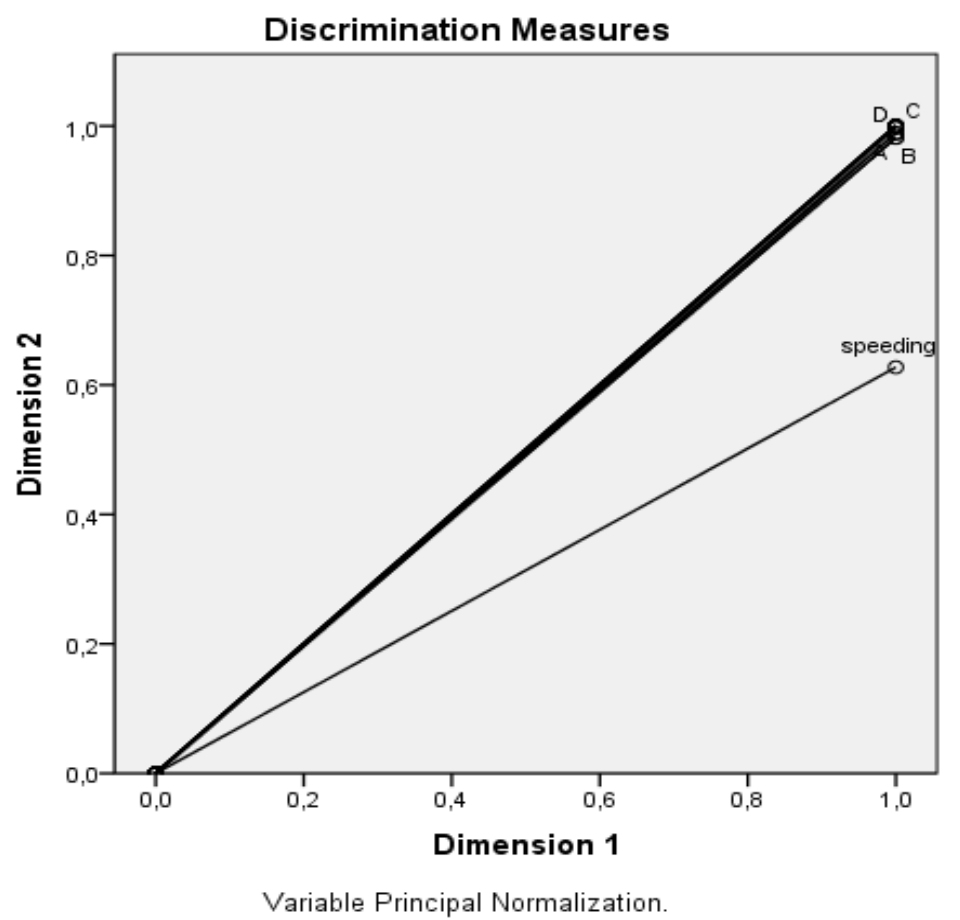

Fig. 4. Dimension of Multidimensional Scaling causes of traffic accidents with injuries and deaths by driver's age

This model explains more than $95 \%$ of the variability of causes of traffic accidents by age of drivers. Driving over the speed limit has proven to be a significant correlating factor in the causes of traffic accidents with injuries and deaths due to the age of the driver. Refer to Fig. $\mathbf{5}$ for a more detailed overview of how driving over the speed limit is connected to driver's age.

The horizontal axis shows the age categories of the drivers. On the vertical axis, there is the average number of traffic accidents with injuries and deaths per year; it is calculated per 100,000 inhabitants of each particular age group. Driving over the speed limit (black curve) is a significant problem for young drivers aged 18 years and above, which is decreasing rapidly with the growing age of drivers. Therefore, we can state that this is the main reason for the predominant prevalence of young drivers in this statistics. 


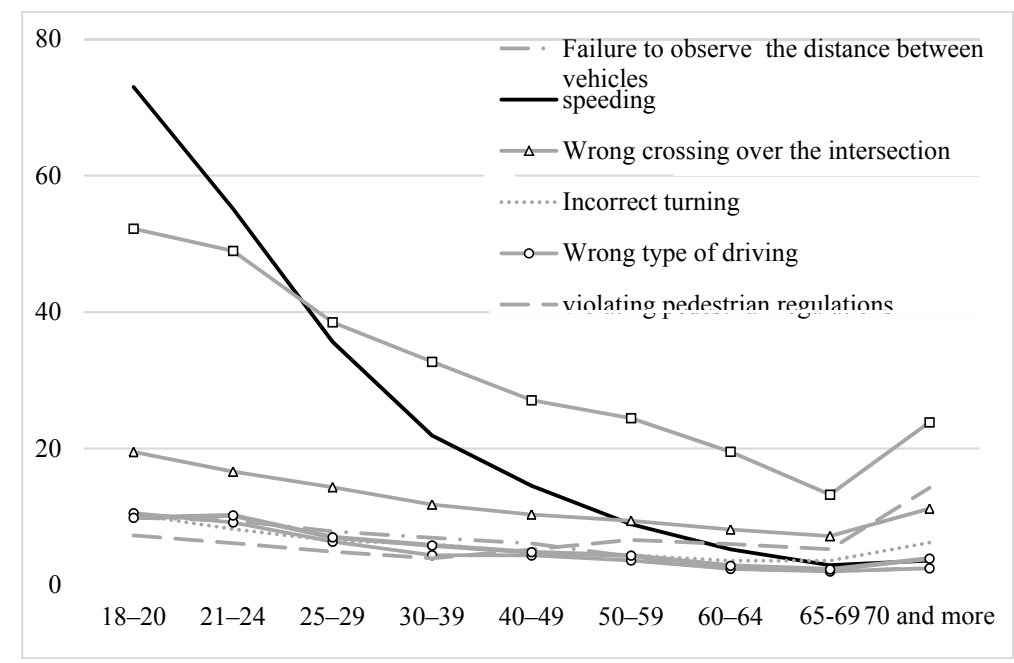

Fig. 5. Average number of traffic accidents per 100,000 inhabitants/year grouped by cause and age of a driver, perpetrator of traffic accident, Slovakia 2007-2018. Source of data: ISDN [14]

\section{Discussion}

Training, information, regulation and monitoring, directed at the individual road user and a strong lack of trust in the road user's ability and willingness to behave correctly, have been key features of traditional traffic safety policy [5].

In Slovakia, a new law came into effect in 2015, increasing fine for driving over the speed limit. However, in practice, the targeted measure did not produce a measurable fall in accident rates, caused by speeding.

One possible explanation is the low effectiveness of law enforcement. There is no profile measurement of speed by camera systems in Slovakia. Detection of such cases by continuous monitoring using digital technologies has been proven for many years in the United Kingdom, the Netherlands, Sweden, Norway [16], Austria and the Czech Republic [7]. Establishing a profile rate measurement of speed in the United Kingdom in particular meant reducing the number of road traffic fatalities by about 100 people per year. The support for records from these devices must be such as to be acceptable as evidence in court. Also, according to the study [17], the profile of speed measurement has a greater effect on reducing the number of people, killed in traffic accidents, than police patrols.

Especially in case of young drivers, we can study a growing trend in Slovakia of young drivers not respecting speed limits. Below, we provide concrete cases of not adjusting driving style to the type and condition of road communication. The cases are sorted in descending order, according to their frequency:

1. Not adapting speed to driver's skills;

2. Not adapting speed to road conditions and road nature;

3. Not adapting speed to weather conditions;

4. Not adapting speed to type of vehicle and cargo properties;

5. Not adapting speed to the visibility and view of the road.

Young drivers aged 20, who have been holding driver's license for very short time, knowingly drive over the speed limit and violate the driver's duties [18]. According to OECD material, traffic accidents of young drivers are very frequent due to the lack of perceived risk [19].

The results of increased traffic accident rates of young drivers point to the need for more intensive training, which should be reinforced by increased driving control. The probationary period should apply to every driver with a driving license of B category, who in a period of several years since obtaining their driver's license repeatedly violates the road traffic rules in a serious way or fails to adapt the speed to traffic conditions. The first year after obtaining the driving license is not as critical as the second year, based on traffic accident records. From this view, the trial period should last at least 2 years. Mandatory participation in driving training, psychological training 
with a traffic psychologist, and road traffic police check all could be more effective penalties than a one-off payment of the fine. Recurrence of drivers' risky behaviour should be prevented by precautionary measures. Training in driving schools, or driving simulators cannot replace the time, needed to change the thinking of a young driver, only miles of experience behind the wheel in real road traffic can do that. A driver is forced to predict behaviour and reactions of other road users and will need to overcome unusual situations.

In case of drivers with three or more offences, third and following road traffic serious or speeding occurrences, penalties should rapidly increase, or their driving license should be confiscated. Essentially, sanctions should be targeted at the riskiest drivers with greatest priority.

\section{Conclusion}

1. The European Union's progress in enhancing road traffic safety has been impressive. The EU cut the number of fatal road crashes by $43 \%$ between the years 2000 and 2010 and reduced them further by $20 \%$ from 2011 to 2017 . However, progress has stalled recently, and has been unequally distributed between different countries and groups of road users [19].

2. For further improvement of the results, it is beneficial to take examples of good practice from countries that have the long term lowest number of people, killed in traffic accidents.

3. The frequency of road fatalities among young drivers in Slovakia has not decreased at the same pace as for the overall average. Therefore, these vulnerable groups of road users deserve special attention from policymakers.

4. The study shows that young drivers are significantly different from older drivers by causing the road accidents due to inexperience and frequent speeding. The lack of experience, combined with inadequate self-confidence and tendency to drive more risky, which leads to an increased number of injured and killed victims of traffic accidents. For elimination of this kind of behaviour, there had already been introduced a probationary period in several EU countries.

\section{Acknowledgement}

This article was written as part of scientific research task No. 161 "Methods of processing information relevant in context of the police force" being solved at the Academy of the Police Force in Bratislava.

\section{References}

[1] Aksan, N., Dawson, J. D., Emerson, J. L., Yu, L., Uc, E. Y., Anderson, S. W., Rizzo, M. (2012). Naturalistic Distraction and Driving Safety in Older Drivers. Human Factors: The Journal of the Human Factors and Ergonomics Society, 55 (4), 841-853. doi: http://doi.org/10.1177/0018720812465769

[2] White Paper of 28. March 2001: Roadmap to a Single European Transport Area - Towards a competitive and resource efficient transport system COM(2001) 144 final version. Available at: https://eur-lex. europa.eu/LexUriServ/LexUriServ.do?uri=COM:2011:0144:FIN:en:PDF

[3] Corben, B. F., Logan, D. B., Fanciulli, L., Farley, R., Cameron, I. (2010). Strengthening road safety strategy development “Towards Zero" 2008-2020 - Western Australia's experience scientific research on road safety management SWOV workshop 16 and 17 November 2009. Safety Science, 48 (9), 1085-1097. doi: http://doi.org/10.1016/j.ssci.2009.10.005

[4] De Haven, H. (2000). Mechanical analysis of survival in falls from heights of fifty to one hundred and fifty feet. Injury Prevention, 6 (1), 62-68. doi:1 http://doi.org/10.1136/ip.6.1.62-b

[5] Evans, L. (Ed.) (2004). Traffic safety. Bloomfield: Science Serving Society, 444.

[6] OECD/ITF: Road Safety Annual Report 2011. Available at: https://www.itf-oecd.org/road-safetyannual-report-2011

[7] Marcinek, M. (2016). The Current Situation in Vehicle Safety System. Archibald Reiss Days. Belgrade: Academy of Criminalistic and Police Studies, 2, 462-472.

[8] Goodvin, P. (2013). Peak Travel, Peak Car and the Future of Mobility: Evidence, unresolved issues, policy implications and research agenda. OECD/International Transport Forum Long Run Trends in Car Use, ITF Round Tables, No. 152, OECD Publishing/ITF. doi: http://doi.org/10.1787/5k4c1s31876d-en 
[9] OECD/ITF: Road Safety Annual Report 2018. Available at: https://www.itf-oecd.org/road-safety-annual-report-2018

[10] European Commission with target EU 2020

[11] Annual Accident Report (2018). European Commission. Directorate General for Transport. Available at: https://ec.europa.eu/transport/road_safety/sites/roadsafety/files/pdf/statistics/dacota/asr2018.pdf

[12] Elvik, R. (1999). Can injury prevention efforts go too far? Reflections on some possible implications of Vision Zero for road accident fatalities. Accident Analysis and Prevention, 31 (3), 265-286. doi: http:// doi.org/10.1016/s0001-4575(98)00079-7

[13] Belin, M.-Å., Tillgren, P., Vedung, E. (2012). Vision Zero - a road safety policy innovation. International Journal of Injury Control and Safety Promotion, 19 (2), 171-179. doi: http://doi.org/10.1080/174 57300.2011 .635213

[14] Records of the Police force of the Slovak Republic.

[15] Hajdúková, T. (2015). Improving Road Safety and Eliminating Consequences of Traffic Accidents in the European Union: Part VII. Selected Social and Political Aspects of Internal Security. New York: Iglobal Writer Inc., Pro Pomerania Foundation Poland, 123-134.

[16] Elvebakk, B., Steiro, T. (2009). First principles, second hand: Perceptions and interpretations of vision zero in Norway. Safety Science, 47 (7), 958-966. doi: http://doi.org/10.1016/j.ssci.2008.10.005

[17] Elvik, R., Vaa, T. (2004). The handbook of road safety measures. Oxford: Elsevier, 700.

[18] Kuhnimhohf, T., Armouogum, J., Buehler, R., Dargay, J., Denstadli, J. M., Yamamoto, T. (2012). Trends in Young Adults' Behavior. Evidence from Six Industrialized Countries. 90th TRB Annual Meeting. IFSTTAR. Working document

[19] EU Strategic Action Plan on road Safety (2018). Europen Commision, 7. Available at: https://eurlex.europa.eu/resource.html?uri=cellar \%3A0e8b694e-59b5-11e8-ab41-01aa75ed71a1.0003.02/DOC_2\&format $=$ PDF 